\title{
Discours
}

Revue de linguistique, psycholinguistique et

informatique. A journal of linguistics, psycholinguistics

and computational linguistics

$10 \mid 2012$

Multidisciplinary Perspectives on Signalling Text

Organisation

\section{Genre Realized in Theme: The Case of News Reports and Commentaries}

Julia Lavid, Jorge Arús and Lara Moratón

\section{OpenEdition}

\section{Journals}

Electronic version

URL: http://journals.openedition.org/discours/8623

DOI: 10.4000/discours.8623

ISSN: 1963-1723

\section{Publisher:}

Laboratoire LATTICE, Presses universitaires de Caen

\section{Electronic reference}

Julia Lavid, Jorge Arús and Lara Moratón, « Genre Realized in Theme: The Case of News Reports and Commentaries », Discours [Online], 10 | 2012, Online since 16 July 2012, connection on 19 April 2019. URL : http://journals.openedition.org/discours/8623 ; DOI : 10.4000/discours.8623

\section{c) $(1) \Theta$}

Discours est mis à disposition selon les termes de la licence Creative Commons Attribution - Pas d'Utilisation Commerciale - Pas de Modification 4.0 International. 

Revue de linguistique, psycholinguistique et informatique

\title{
Genre Realized in Theme: \\ The Case of News Reports and Commentaries
}

\author{
Julia Lavid \\ Dpt. English Philology I, Faculty of Philology \\ Universidad Complutense de Madrid \\ Jorge Arús \\ Dpt. English Philology I, Faculty of Philology \\ Universidad Complutense de Madrid \\ Lara Moratón \\ Dpt. English Philology I, Faculty of Philology \\ Universidad Complutense de Madrid
}





\title{
Genre Realized in Theme: The Case of News Reports and Commentaries
}

\author{
Julia Lavid \\ Dpt. English Philology I, Faculty of Philology \\ Universidad Complutense de Madrid \\ Jorge Arús \\ Dpt. English Philology I, Faculty of Philology \\ Universidad Complutense de Madrid \\ Lara Moratón \\ Dpt. English Philology I, Faculty of Philology \\ Universidad Complutense de Madrid
}

\begin{abstract}
The purpose of this paper is to analyze how the clausal thematic features observed in two newspaper genres - news reports and commentaries - can be interpreted as textual signals of their different generic characterization. This is done through the qualitative and quantitative analysis of a sample consisting of thirty-three English texts, divided into two groups of seventeen news reports and sixteen commentaries, respectively. The analysis focused on the following thematic features: (1) the experiential elements selected as Thematic Heads; (2) the semantic nature of the nominal elements realizing these Heads and their internal structure; (3) the textual and interpersonal thematic choices as part of a multiple theme. The analysis reveals that each newspaper genre prefers certain thematic features and that the differences between the two genres are statistically significant. It is suggested that these thematic preferences can be attributed to genre-related variables such as the communicative purpose or the subject matter of the text.
\end{abstract}

Keywords: newspaper genres, thematic features, reports, commentaries

\section{Introduction}

Within the now consolidated research strand of media discourse analysis, numerous studies have focused on certain linguistic features of the different newspaper genres, such as news stories, reports, or editorials.

News stories and reports have been extensively studied from different perspectives (Van Dijk, I988; Bell, 1991; Fairclough, 1995; White, 1998; Scollon, 1998; among others); newspaper commentaries, conversely, have received less theoretical and empirical attention, though contrastive work on commentaries (Wang, 2008a and b), opinion columns (Dafouz, 2008) and editorials (Alonso Belmonte, 2007; Hawes \& Thomas, 1996; Lavid, Arús \& Moratón, 2009; Tirkkonen-Condit, 1996) is offering interesting results for the description of opinion newspaper genres across languages and cultures. 
This study attempts to advance knowledge in this area by focusing on the thematic features of news reports and commentaries as textual signals of their different generic characterization ${ }^{1}$. With our analysis we hope to contribute to a profitable line of research which investigates the correlations between genre and thematic content, i.e. how different genres are characterized by different ways of starting their clauses and, therefore, how they evolve textually (see Lavid, 2000; Eiler, 1986; Francis, 1989 and 1990; Ghadessy, 1995; Fries \& Francis, 1992; Nwogu \& Bloor, 1991; among others).

The paper is structured as follows: section 2 provides a description of the genres analyzed here; section 3 sets the research questions guiding our work; section 4 briefly introduces the theoretical framework underlying our research; section 5 shows the data used in our study and explains the methodology deployed; the results obtained are explained and discussed in detail in section 6, and the concluding section 7 provides a wrap-up and offers some pointers to the future.

\section{Two newspaper genres: reports and commentaries}

Genre refers to language use in a conventionalized communicative setting in order to give expression to a specific set of communicative goals of a disciplinary or social institution, which give rise to stable structural forms by imposing constraints on the use of lexico-grammatical as well as discoursal resources (Bhatia, 2002). Studies of genre aim to capture how writers achieve their communicative purposes by using various structural forms, constructing different focuses and manipulating topics and readers by using various linguistic devices. There is a rich tradition of genre studies within Systemic Functional Linguistics (SFL), the theoretical framework used in our research (see section 4 below). Much of the SFL-based literature on genre is concerned with the use of genre in educational contexts and therefore falls beyond the scope of this paper. Other studies closely related to the delimitation of different genres are Ghadessy (1995), who identifies specific characteristics of thematic development in written sports commentaries as opposed to other written genres, Christie and Martin (2005), where contributors spell out the particularities of different genres used in working and educational settings and show how these genres shape people's subjectivities, and Muntigl and Gruber (2005), where the identification of genres is approached from an SFL perspective, as well as from other theoretical frameworks.

Turning now more specifically to the genres of our concern in this paper, for White (1998: 243) news reports are "grounded in communicative events such as speeches, interviews and press releases", which "act primarily to represent, not activity sequences, but the points of view of various external sources". They are classified

1. "Signals" are to be interpreted in a rather broad sense in this paper. Rather than referring to a more or less intentional strategy deployed by writers to indicate, for instance, generic features, the term "signal" is used here in the sense of "reflex" or "manifestation". 
as communicatively-based rather than event-based. A news report should strive to remain objective and should use neutral language while presenting a diversity of opinions, voices, and perspectives of the event, incident, or issue under discussion.

News commentaries are opinion articles with the important communicative function of contributing to the formulation of certain "preferred" viewpoints about the world. The function of news commentaries within the larger context of newspaper coverage is to offer newspaper readers a distinctive and sometimes authoritative voice that speaks to the public directly about matters of public importance (Wang, 2008a: 170). Usually written by academics, journalists and other experienced native language writers (Wang, 2007: 3), they exert an important influence on political opinion-formation, both on the everyday reader and on the institutional and/or elite members of a society (Van Dijk, 1998).

According to the definitions provided above, the communicative purposes of news reports and commentaries differ in several respects. While the main communicative purpose of news reports is basically informative, the goal of news commentaries is analytical, evaluative and persuasive. In functional theories of language, contextual differences - such as the communicative purpose of a given genre- are reflected in the linguistic features used by language producers. It should be expected, therefore, that the different communicative purposes which characterize these two newspaper genres would be reflected in their thematic features. This is the basis for the research questions presented below.

\section{Research questions}

Following the line of reasoning outlined above, this study examines the clausal thematic features used by writers when constructing their messages in news reports and commentaries. More specifically, the present study proposes the following research questions:

- What are the thematic features preferred by news reports and commentaries? Are there any differences in this selection?

- If there are differences, can these be interpreted as textual signals, along with other linguistic choices, of the different genres to which these texts belong?

These research questions are investigated through the empirical analysis of a sample of news reports and commentaries, as explained below.

\section{Theoretical framework}

Our analysis applies the SFL-based model proposed in Lavid, Arús \& Zamorano (2010) for the contrastive study of the message structure of English and Spanish. In 
this section we briefly outline the main features of the SFL descriptive apparatus, focusing on those aspects pertinent to the research presented in this paper.

SFL distinguishes three layers — called metafunctions - of meaning in language: the ideational, concerned with the resources to construe human experience and realized by the system of transitivity; the interpersonal, concerned with the resources available to speakers to interact with one another (and thus make requests, offers, statements and questions) and realized by the system of mood; and the textual, concerned with the resources to construct text and mainly realized by the system of theme (Halliday \& Matthiessen, 2004). Of these three metafunctions, only the ideational and the textual are dealt with in the analysis presented here, so this section will be circumscribed to the systems realizing these two ${ }^{2}$.

\subsection{Process types}

In order to construe experience, we resort to a number of process types consisting of Processes (realized by verbal groups), participants (realized by groups other than verbal, often nominal) and, sometimes, circumstances (typically realized by adverbial and prepositional groups). In what follows, we present the main process types and their participants, illustrating these by means of self-explanatory examples rather than providing tiresome definitions:

- material, expressing doings and happenings; the main participants are the Actor, the Goal, the Recipient and the Scope (which is not affected by the performance of the process the way the Goal is, but rather complements the meaning of the Process itself), as in examples [I-4] (Halliday \& Matthiessen, 2004: 179-197);

[I] 'Peter' 'gave' 'Mary' 'a letter'

Actor Process Recipient Goal

[2] 'Mary' 'was given' 'a letter' 'by Peter'

Recipient Process Goal Actor

[3] 'Mary' 'is running'

Actor Process

[4] 'Mary' 'is playing' 'guitar'

Actor Process Scope

- mental, expressing consciousness, emotions and the like; the main participants are the Senser and the Phenomenon, as in examples [5-7] (Halliday \& Matthiessen, 2004: 197-210);

2. This does not mean we will not be looking at impersonal Themes, which we will. However, as these just concern Adjuncts, there is no real need to understand the resources offered by the interpersonal metafunctions to differentiate between statements, questions, etc. 


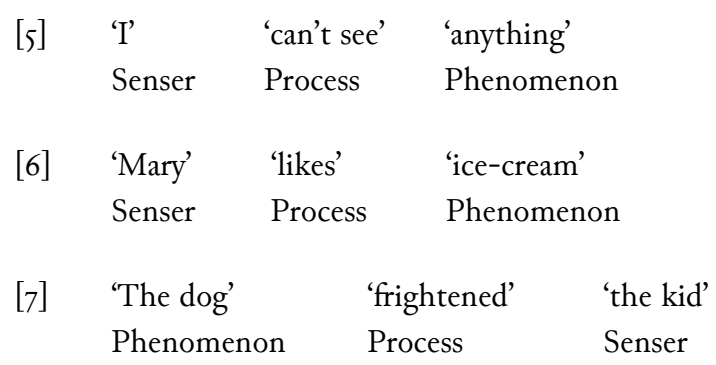

- verbal, realized by clauses of saying; the main participants are the Sayer and the Verbiage, which is what is said when this is represented as a participant [8] instead of as a report [9] or a quote [Io]. There is often also a Receiver, as illustrated in [8] (Halliday \& Matthiessen, 2004: 252-256);

$\begin{array}{llll}\text { [8] 'She' } & \text { 'asked' } & \text { 'me' } & \text { 'a question' } \\ \text { Sayer } & \text { Process } & \text { Receiver } & \text { Verbiage } \\ \text { [9] “'I'm quite tired now”' } & \text { 'she' } & \text { 'replied' } \\ \text { Report } & & \text { Sayer } & \text { Process } \\ & & & \\ \text { [Io] } & \begin{array}{l}\text { 'She' } \\ \text { Sayer }\end{array} & \text { 'said' } & \text { 'she was quite tired' } \\ & \text { Process } & \text { Quote }\end{array}$

- relational, expressing being, having and circumstantial relations such as being at, being with, being about, etc.; the main participants are the Carrier and the Attribute in " $a$ is a kind of $b$ " processes (typically non-reversible, and called attributive) such as [ $\left.\mathrm{II}^{-} \mathrm{I} 3\right]$; when the relation is one of "a equals b" (typically reversible, and known as identifying) the main participants are the Token and the Value, as in [I4-I9] (Halliday \& Matthiessen, 2004: 210-248).

[II] 'His father' 'is' 'a banker'

Carrier Process Attribute

[I2] 'I' 'have' 'no brothers or sisters'

Carrier Process Attribute

[13] 'The movie' 'is' 'about a poor family'

Carrier Process Attribute

[I4] 'This' 'is' 'the best movie I've ever seen'

Token Process Value

[I5] 'The best movie I've ever seen' 'is' 'this one'

Value Process Token




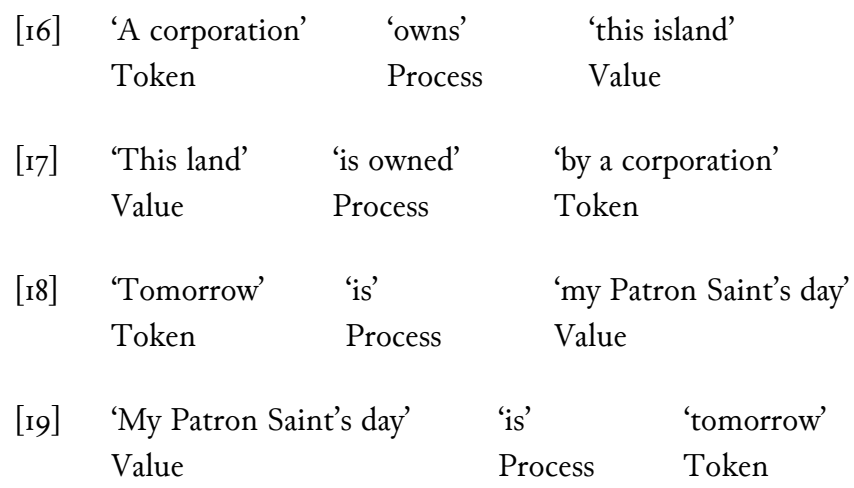

Examples [I-19] illustrate the main process types with their most nuclear participants. All of these participants appear in Tables 1 and/or 2 in section 6, below. These tables include three more participants which are less nuclear and therefore have not been included in the examples above, i.e. the Attributor, the Assigner and the Inducer, as well as the lexical realization there, typical of another process type, i.e. existential. The Attributor, the Assigner and the Inducer are agents in attributive relational [20], identifying relational [2I] and mental [22] processes, respectively. As shown in [23], there does not fulfill any ideational role; it is used by the speaker to allow "the addressee to prepare for something that is about to be introduced" (Halliday \& Matthiessen, 2004: 257).

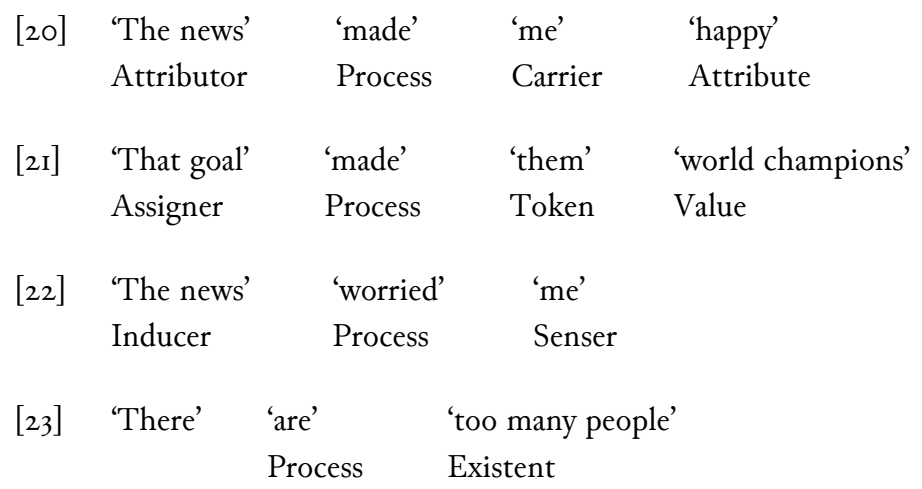

\subsection{The textual structure}

Textual meaning is primarily realized by thematic structure, which in turn consists of the Theme, i.e. the beginning of the clause, and the Rheme, i.e. the rest of the clause. The Theme includes the first ideational participant as well as anything that may precede this, and its function is that of locating and orienting the clause within its context (Halliday \& Matthiessen, 2004: 64). This means that the way we start a clause helps us integrate it into the general context of our discourse while at the same time determining the way in which the new information provided by the clause will then unfold. The resources to present this new information depend 
on the so-called information unit (Halliday \& Matthiessen, 2004: 87), into which we will not delve here. All this is particularly valid for written language, where intonation can play no role. When speaking, on the other hand, the thematic and informational arrangement of elements in the clause is less important, as spoken discourse is more fragmentary than written discourse and intonation is the key factor to signal new information.

Halliday and Matthiessen (2004: 79-87) distinguish three basic types of Theme, i.e. topical Theme, which is the one all clauses have and that we here call "ideational", as in [24], and two other kinds of Theme which may or may not appear, namely textual $[25]$ and interpersonal Theme $[26]$. As we can see in $[25,26]$, the textual and interpersonal Themes always precede the ideational Theme. When there is only an ideational Theme, the clausal Theme is said to be simple; when there is also a textual and/or an interpersonal component, the Theme is said to be multiple.

[24] 'We' 'went to the cinema'

Theme (topical)

Rheme

[25] 'After the cinema'

'we' Theme (textual)

Theme (topical)

'went for an ice-cream'

Rheme

Theme

$\begin{array}{lllll}\text { [26] 'After that,' } & \text { 'unfortunately' } & \text { 'we' } & \text { 'had to go home' } \\ \text { Theme (textual) } & \text { Theme (int.) } & \text { Theme (topical) } & \text { Rheme }\end{array}$

Theme

Drawing on Halliday \& Matthiessen's model, in Lavid, Arús \& Zamorano (20IO) we expanded the description for further delicacy. Our extended model of Theme is the one applied to the analysis presented in this paper. In this model we distinguish between the Inner Thematic Field and Outer Thematic Field. The former includes the Thematic Head and any possible, but not necessary, PreHeads. The Outer Thematic Field, which is not an obligatory segment, includes textual and interpersonal thematic elements preceding the Inner Thematic Field. We now provide a description of these thematic constituents.

The Thematic Head is defined as the first nuclear experiential constituent within the main clause; it is central to the unfolding of the text by allowing the tracking of the discourse participants (see Lavid, Arús \& Zamorano, 20Io). In English declaratives the Thematic Head usually conflates with the Subject or, more markedly, the Complement in preverbal position of the main clause, as in example [27] below (underlined). In existential clauses, the Thematic Head is there, the only case in which the Thematic Head is not an experiential participant, as in example [28].

[27] The commitment of Sudan's government to the CPA has always been equivocal. (Comment. I) 
[28] There is also the risk that nuclear weapons may fall into the hands of non-state actors, such as terrorist groups.

(Comment. 2)

Besides these typical Thematic Heads, there are also other more marked realizations such as thematic equatives [29] and predicated Themes [30], among others.

[29] What is most needed now is to build an international consensus on a strategy to implement fully the 2005 Comprehensive Peace Agreement (CPA) for Sudan.

(Comment. I)

[30] It is Saudi Aramco that has been responsible for the weakening oil price, pushing more oil on the market since the energy summit in Jedda.

(Report 2)

The PreHead element is any circumstantial and/or finite element preceding the Thematic Head, such as "since the civil war's end in 2005 ", in [31].

[3I] Indeed, since the civil war's end in 2005, the Sudan People's Liberation Army (SPLA) in the South has frequently had to confront militias that operate as government proxies. (Comment. I)

Interpersonal Themes are elements in clause-initial position immediately preceding the Thematic Head and expressing the attitude and the evaluation of the speaker with respect to his/her message, including those expressing modality and polarity. Examples [32] and [33] below illustrate this type of Theme:

[32] Unfortunately, the discussion between countries on trade nowadays is very much a dialogue of the deaf, with countries spouting platitudes at one another, but no enforceable and verifiable commitments agreed upon.

(Comment. 7)

[33] Perhaps inevitably, the SCO —and Russia and China as its leading membersregards NATO's increased presence in the region with some mistrust.

(Comment. 5)

Textual Themes are those elements in clause-initial position which are instrumental in the creation of the logical connections in the texts, such as linkers, binders, and other textual markers. Some examples of textual Themes are the elements "first", "second" and "third" in example [34] below:

[34] First, the EU still spends far more of its resources subsidizing declining sectors than preparing for the future. [...] Second, Europe has failed to introduce an independent European Research Council to ensure that funding is allocated on the basis of scientific merit. [...] Third, European resources are fragmented, and this hampers European competitiveness.

(Comment. II) 


\section{Data and procedure}

\subsection{Data}

The data used for this study is a sample of the themes of a total of 9or clause complexes (all of them declarative with the exception of two interrogatives and four imperatives) belonging to two groups of texts, all of them collected from published sources between 2008 and 2009. The first group consists of seventeen newspaper commentaries written by expert writers or journalists extracted from the Project Syndicate, an international association of quality newspapers that publishes commentaries by prominent figures in the world's foremost newspapers on topics ranging from economics, political and international affairs to science and philosophy (see http://www.project-syndicate.org). The commentaries total 576 clauses and 22,322 words. The second group consists of sixteen news reports extracted from the news section of the online version of The Times (http://www.timesonline.co.uk) newspaper, adding up to 325 clauses made up of 8,743 words.

\subsection{Procedure}

As said above, our analysis draws upon Lavid, Arús \& Zamorano (20I0). The clausal features selected for analysis capture the three main types of meaning represented by the category of Theme in the linguistic literature: experiential, interpersonal and textual. For the analysis of the experiential meaning, we focused on the category of the Thematic Head, since this captures the nuclear experiential choice within the clause and is central for the text's thematic development. We also inspected the semantic nature of the nominal elements functioning as Thematic Heads and their internal structure. To complete the metafunctional analysis, we also included interpersonal and textual Themes as part of a multiple Theme in our analysis. The procedure was as follows:

- we segmented the texts into clause complexes, consisting of a main clause preceded or followed by one or more subordinate clauses. When the subordinate clause precedes the main clause, the former is treated as PreHead, as seen in example [45] in 6.I, below;

- we assigned the labels "Thematic field", "Outer Thematic Field" and "Inner Thematic Field", respectively;

- we searched for the Thematic Head in each main clause;

- we inspected the experiential roles (e.g. Actor, Goal, Sayer, Recipient, Senser, Phenomenon, Carrier, Token, etc.), selected as Thematic Heads in main clauses and tallied their frequencies. Examples [35], [36] and [37] below illustrate several cases of Thematic Heads functioning as Carrier, Actor, and Sayer, respectively;

[35] The negative stigma attached to IMF financing is a thing of the past. (Comment. 8) 
[36] A high-powered Russian delegation recently arrived in Juba, the South Sudanese capital, with the proclaimed aim of "playing a more active role on the African continent". (Comment. I)

[37] Shakour Shaalan, the fund's executive director, said IMF staff, and notably female staff, "are not at all happy" with Mr Strauss-Kahn, whose amorous adventures in France have earned him the epithet le grand seducteur.

(Report I)

- we looked at the nominal elements realizing the Thematic Heads and analyzed them as either concrete or abstract nouns. As we will see in section 6.2, below, concrete nouns refer to human participants, titles, pronouns, groups of people or institutions, whereas abstract nouns refer to qualities or mental concepts;

- we examined the internal complexity of the nominal elements and tallied their frequencies. We considered as complex those Nominal Groups with long, varied and/or multiple Heads or with Modifiers. Example [38] illustrates a simple Nominal Group functioning as Thematic Head, whereas in [39] the complex Nominal Group consists of a determiner ("the"), a head ("agreement"), and two Postmodifiers ("by the American and Russian presidents" and "to renew strategic arms reductions"):

[38] The CPA ended Africa's longest civil war, which had left behind over two million dead.

(Comment. I)

[39] The agreement by the American and Russian presidents to renew strategic arms reductions has revived hope for the global abolition of nuclear arms.

(Comment. 3)

- we identified and analyzed Interpersonal and Textual Themes and tallied their frequencies.

\section{Results}

In the following subsections we will present and comment on the results of our analysis of the various different aspects of clausal thematic choices, beginning with the results of the experiential roles selected as Thematic Heads. For each aspect, the statistical significance of differences between genres was calculated by means of the chi-square test.

\subsection{Experiential roles of Thematic Heads}

When comparing the types of experiential role selected as Thematic Head we found interesting commonalities and differences between the two newspaper genres under study. Thus, the experiential role of Actor presents very high frequencies in both genres, with no statistically-significant differences between them $(28.31 \%$ in news 
reports vs. $28.12 \%$ in commentaries), as shown in Tables I and 2 below. This is probably due to the fact that both genres deal with current events, which accounts for the high percentage of material processes in both groups of texts.

\begin{tabular}{|c|c|c|}
\hline Experiential roles & Absolute frequency & Relative frequency (\%) \\
\hline Sayer & IO4 & 32.00 \\
\hline Actor & 92 & $28.3 \mathrm{I}$ \\
\hline Carrier & 45 & $\mathrm{I} 3.85$ \\
\hline Goal & 20 & 6.15 \\
\hline There & 20 & 6.15 \\
\hline Senser & I0 & 3.08 \\
\hline Process & 8 & 2.46 \\
\hline Token & 8 & 2.46 \\
\hline Value & 6 & $\mathrm{I} .85$ \\
\hline Attributor & 4 & $\mathrm{I} .23$ \\
\hline Recipient & 3 & 0.92 \\
\hline Scope & 2 & 0.62 \\
\hline Verbiage & 2 & 0.62 \\
\hline Assigner & $\mathrm{I}$ & $0.3 \mathrm{I}$ \\
\hline Phenomenon & $\mathrm{I}$ & $0.3 \mathrm{I}$ \\
\hline Total & 325 & I00 \\
\hline
\end{tabular}

Table 1. Experiential roles as Thematic Heads in news reports

\begin{tabular}{|c|c|c|}
\hline Experiential roles & Total frequency & Relative frequency (\%) \\
\hline Actor & $\mathrm{I} 67$ & 28.99 \\
\hline Carrier & $\mathrm{I} 62$ & 28.12 \\
\hline Token & 72 & $\mathrm{I} 2.50$ \\
\hline Goal & 48 & 8.33 \\
\hline Senser & 28 & 4.86 \\
\hline Sayer & 22 & 3.82 \\
\hline Value & $2 \mathrm{I}$ & 3.65 \\
\hline Process & $\mathrm{I} 6$ & 2.78 \\
\hline Attribute & 9 & $\mathrm{I} .56$ \\
\hline Attributor & 9 & $\mathrm{I} .56$ \\
\hline Phenomenon & 6 & $\mathrm{I} .04$ \\
\hline Scope & 3 & 0.52 \\
\hline Verbiage & 3 & 0.52 \\
\hline There & 3 & 0.52 \\
\hline Recipient & 2 & 0.35 \\
\hline Inducer & 2 & 0.35 \\
\hline Assigner & 2 & 0.35 \\
\hline Receiver & $\mathrm{I}$ & 0.17 \\
\hline Total & 576 & $\mathrm{I}$ \\
\hline
\end{tabular}

Table 2. Experiential roles as Thematic Heads in commentaries 
However, when examining other experiential roles selected as Thematic Heads, we can observe certain interesting differences:

- Sayers are much more frequently selected as Thematic Heads in news reports $(32 \%)$ than in commentaries $(3.82 \%)$, and this difference is statisticallysignificant $(\mathrm{p}<0.05)$. This can be explained by the high number of citations used in news reports with the purpose of presenting a diversity of opinions, voices and perspectives on the event, incident or issue under discussion, as illustrated in example [40] below:

[40] Mr Tilmant said the bank had the trust of its customers and had not seen a large outflow of funds.

(Report 7)

- Carriers/Tokens are more frequently selected in commentaries $(28.12 \%+$ $\mathrm{I} 2.50 \%=40.62 \%)$ than in news reports $(13.85 \%+2.46 \%=\mathrm{I} 6.31 \%)$, and this difference is statistically-significant $(\mathrm{p}<0.05)$. This can be interpreted as a textual device used by writers to give their opinion in what seems to be an objective and impartial way. By using relational processes, writers of commentaries become invisible and manage to detach themselves from their opinions. For example, while a personally visible writer would use phrases like "I propose...", the invisible writer would prefer "It is clear that..." (Davies, 1989). Examples [41] and [42] below illustrate this use:

[4I] After all, the oppressive nature of the regime in Khartoum is at the root of the many conflicts that have torn the country apart.

(Comment. I)

[42] The main expectations are for a reduction of nuclear armaments.

(Comment. 2)

Although the rest of the experiential roles as Thematic Heads present low frequencies in both genres, it is worth pointing out the presence of Goals in fourth place both in reports $(6.15 \%)$ and commentaries $(8.33 \%)$. There is no statisticallysignificant difference between these proportions $(p=0.56)$; the passive voice is used in the two genres under consideration here, for instance, for the thematization of the Goal — as well as the Scope - in material processes, as shown by [43], [44]. Total use of passives is to be considered somewhat higher than the percentages just referred to, as these are only for material processes; occasional passives with mental and verbal processes - with thematized Phenomena, Recipients, Verbiages, reports, etc. - will increase those percentages, yet only slightly, considering the low frequencies of these participants as Thematic Heads. Examples [45], [46] illustrate passives with thematized Phenomenon and Verbiage, respectively.

[43] Jobs will continue to be shed.

(Comment. Io) 
[44] It was downgraded last July.

(Report I3)

[45] As the global financial crisis transforms itself inexorably into economic crisis and now industrial crisis, the cry "where's Europe?" can be heard across the EU.

(Comment. 13)

[46] The details of the deal, which was agreed over the weekend, were announced last night by Wouter Bos, the Finance Minister, Nout Wellink, the central bank governor, and Michel Tilmant, the chief executive of ING.

(Report 4)

One last thing worth pointing out about the results shown in Tables I and 2 concerns the contrast between existential "there" in reports and commentaries. As we can see, "there" is the Thematic Head in $6.15 \%$ of recorded reports vs. only $0.52 \%$ of commentaries $(p<0.05)$, which reflects its use to introduce new information, particularly helpful when reporting news, as illustrated by [47], [48].

[47] Later there were unconfirmed reports that six people were still alive in the rubble of a building.

(Report Io)

[48] There is a growing concern they are being rushed abroad for foreign adoption.

(Report Io)

\subsection{Concreteness of Noun Groups realizing Thematic Heads}

With respect to the degree of concreteness of Noun Groups realizing Thematic Heads, we found statistically-significant differences $(p<0.05)$ between the genres: while news reports prefer concrete Noun Groups as Thematic Heads (63.69\%) rather than abstract ones ( $14.46 \%)$, commentaries present the opposite proportionalities, favouring the use of abstract nouns (40.10\%) over concrete ones (30.90\%).

Concrete Noun Groups in our sample refer to human participants (e.g. Mr. Tiltman, Mr. Strauss-Kahn); titles (e.g. the managing director); pronouns (e.g. she, he, they), groups of people or institutions (e.g. the Government, Microsoft). Abstract nouns refer to qualities or mental concepts (e.g. expectations, results). This shows that news reports are more concerned with individuals or groups of people, while commentaries are more concerned with the exposition and evaluation of ideas.

\subsection{Complexity of Noun Groups as Thematic Heads}

As to the internal structure of the Noun Groups realizing Thematic Heads, the genres present interesting differences. In commentaries Noun Groups tend to be longer and more complex in their internal structure ( $17.20 \%)$ than in news reports $(5.36 \%)$, and this difference is statistically significant. Example [49] illustrates the use of a long Nominal Group as Thematic Head: 
[49] As a result, its ability to maintain services — and the military capacity to respond to any maneuver by the Khartoum government aimed against the peace agreement- is seriously compromised.

(Comment. I)

Examples [50] and [5I] also illustrate two complex Noun Groups as Thematic Heads, with two long Qualifiers introduced by a Past Participle form ("issued...", “elaborated...”):

[50] The most immediate result of the arrest warrant issued for Sudanese President Omar Hassan al-Bashir by the International Criminal Court last month was the expulsion of most aid agencies from the country.

(Comment. I)

[51] The Group's report, Arms Control Revisited: Non-proliferation and Denuclearization, elaborated under the chairmanship of Adam D. Rotfeld of Poland and drafted by the British scholar Ian Anthony of SIPRI, was based on contributions by security analysts from nuclear powers and Poland, as well as from countries previously in possession of nuclear weapons (South Africa) and post-Soviet countries where they were once stored (Belarus, Kazakhstan, an Ukraine).

(Comment. 2)

By contrast, the internal structure of Noun Groups as Thematic Heads in news reports is minimal. The only long Noun Groups in news reports are structures consisting of Noun + Apposition whose purpose is to uniquely identify the discourse participant, as illustrated in [52], [53]:

[52] Dominique Strauss-Kahn, the French head of the International Monetary Fund, escaped dismissal for a one-night stand with a subordinate today, but was denounced by board members for a "serious error of judgment".

(Report I)

[53] Shakour Shaalan, the fund's executive director, said IMF staff, and notably female staff, "are not at all happy" with Mr Strauss-Kahn, whose amorous adventures in France have earned him the epithet le grand seducteur.

(Report I)

The contrast between the complexity of Noun Groups in reports and commentaries reflects the usefulness of nominalizations to pack complex thought — which would congruently be expressed by means of a clause- into groups that can be conveniently handled and presented as thematic or as new information in a lexically dense clause, i.e. a clause with complex groups, in this case nominal. This technique is particularly useful in argumentation (see Halliday \& Martin, 1993, for its key role in the development of scientific writing), which can be expected to be more prominent in commentaries than in reports. 


\subsection{Textual and Interpersonal Themes}

The analysis of the textual Themes revealed that these are much more frequently used in commentaries $(20 \%)$ than in news reports $(6 \%)$, a difference that is statisticallysignificant $(\mathrm{p}<0.05)$. This means that writers of commentaries rely much more on textual Themes as textual signals to organize the logico-semantic relations in texts, probably due to the complexity of the ideas and arguments that are presented to readers. By contrast, news reports rely on other textual devices such as paragraphing. Compare examples [54], [55], with typical textual Themes (italicized below) found in commentaries, and the sequence of clauses with simple thematic fields from a report in [56]. Incidentally, the Inner Thematic Fields in the two examples from commentaries happen to be made more complex by the presence of a circumstantial element preceding the Thematic Head.

[54] Thus, for example, at the SCO summit in August, Russia did not get the support of other members regarding the Georgia conflict.

[55] In any case, while the Swiss authorities' discomfort with the situation is understandable, their decision is disquieting.

(Comment. I4)

[56] Opec's mettle will be tested next week when the cartel assembles in Vienna at a hastily convened meeting to discuss the economic crisis and whether the exporters' club should take action to arrest the fall in the price of crude oil. Mounting alarm over the dwindling rent from oil sales prompted Opec yesterday to bring forward an emergency meeting scheduled for mid-November to next Friday. Together the cartel members have lost about a billion dollars of revenue a day since crude price peaked in July. The benchmark US Light crude price fell $\$ 5$ per barrel on the New York

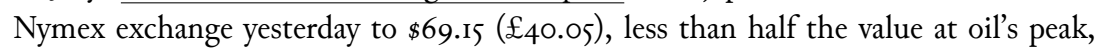
while London's Brent crude futures contract fell to $\$ 65.70$. Evidence of rising oil stocks in America and weakening demand for energy in China's mills and workshops has speeded up oil's decline, but there is no agreement within the cartel over price strategy. Opec hawks, such as Iran and Venezuela, want to shore up the price by turning off the taps, but neither country can afford to cut output and forgo revenues. (Report 2)

Interpersonal Themes are almost non-existent in either group of texts. This is particularly true of reports, where not a single one was found in our set of 17 texts, which is no surprise in a genre where the writer is not expected to interfere with the objective presentation of facts. In commentaries, where one would expect to feel the author's voice, their presence is however limited to a few clauses, with realizations such as "of course", "true" or "admittedly", as illustrated in [57], [58]. This can be due to the fact that interpersonal meaning is rather expressed through other linguistic devices (notably through verbal and/or non-thematic adverbial modality), and writers therefore do not rely so much on thematization for this purpose. 
The process in [59] is an example of both of these resources used together; the epistemic adverb "certainly" and the evidential verb "seem" are used instead of an interpersonal Theme, e.g. "certainly" in thematic position or thematic "apparently" instead of "seem".

[57] Admittedly, there were warnings, but policy makers, particularly in advanced countries, did not follow suit.

(Comment. 8)

[58] Of course, some government spending is desirable or necessary.

(Comment. 6)

[59] Reaching out to the SCO would certainly seem to support NATO's stated objectives. (Comment. 5)

\section{Discussion and concluding remarks}

The comparative analysis of the thematic selection and realization features of the sample of news reports and commentaries used in this study has yielded a number of interesting findings which deserve the attention of the analyst in search of the linguistic signals of a text's genre.

As the analysis has shown, the writers of news reports and commentaries choose different thematic features to structure their messages, preferring certain types over others. Thus, we have seen that in news reports the preferred type of experiential role selected as Thematic Head is the Sayer in a verbal process. This preference, in our view, reflects the need in reports to attribute information to outside sources to give an impression of factuality and objectivity. This contrasts with the preferred use of the Carrier in a Relational process in commentaries, a textual strategy to present the writer's views as unattributed evaluations, as opinions based on facts.

The analysis of the concreteness of Nouns selected as Thematic Heads also reveals interesting differences, which can be interpreted as signals of the different types of subject matter which characterize these two newspaper genres. News reports are usually more about concrete topics and this is reflected in the higher frequency of concrete nouns, referring to individuals, groups of people or institutions. By contrast, commentaries are more about abstract issues, and this is reflected in the higher frequency of abstract nouns. Many of these abstract nouns are nominalizations, a grammatical device that allows the writer to detach himself/herself from the situation, thus giving the impression of impartiality when expressing his/her own views.

As to the internal structure of the Nominal Groups as Thematic Heads, it was observed that they tend to be shorter in news reports, and often clarified through the use of Appositions which clearly identify the referent. This may arguably be 
due to the need to provide a high degree of truth and clarity. In commentaries, by contrast, they tend to be longer and more complex. Pending validation by the analysis and comparison of more data, the preliminary impression is one of academic, formal discourse, of a more elaborate style than that of news reports, which seem to rely more on verbs than on nominalizations for conveying meaning.

The low frequency of interpersonal Themes, which are absent in the case of reports, indicates that writers of these two written newspaper genres prefer to use linguistic means other than Theme for expressing interpersonal meanings. A cursory analysis reveals the use of alternative resources such as verbal modality and evaluative lexis in commentaries.

Interestingly, the different frequencies observed in the use of textual Themes are a clear signal of the different textual structures which characterize these two genres. In news reports textual Themes are not frequent since the textual organization relies on paragraphing. Each paragraph reports a finding or a reporter's comment. By contrast, textual Themes are a more important tool for writers of commentaries. They often rely on textual Themes to scaffold the text's argumentative structure, and to signal logico-semantic relations between complex ideas.

In conclusion, the micro-thematic analysis carried out in this study has revealed interesting differences between news reports, on the one hand, and commentaries, on the other, which can be interpreted as linguistic signals of the different genres to which these texts belong. Further work at a macro-structural level (e.g. thematic progression patterns, distribution of themes in text stages) is currently under way (Lavid, Arús \& Moratón, forthcoming), and will complement the results of this initial study.

\section{References}

Alonso Belmonte, I. (ed.) 2007. Revista electrónica de lingüística aplicada: Different Approaches to Newspaper Opinion Discourse, special issue I. Asociación Española de Lingüística Aplicada (AESLA).

BeLL, A. 199I. The Language of News Media. Oxford (U.K.) - Cambridge (Mass.): Blackwell.

Bhatia, V.K. 2002. A Generic View of Academic Discourse. In J. Flowerdew (ed.), Academic Discourse. Harlow - London - New York: Longman: 2I-39.

Christie, F. \& Martin, J. (eds) 2005. Genre and Institutions. Social Processes in the Workplace and School. London: Continuum [ $2^{\text {nd }}$ edition].

DAvies, F. 1989. Reading between the Lines. ELR seminar paper. University of Birmingham.

DAfouz, E. 2008. The Pragmatic Role of Textual and Interpersonal Metadiscourse Markers in the Construction and Attainment of Persuasion: A Cross-Linguistic Study of Newspaper Discourse. Journal of Pragmatics 40 (I): 95-II3.

EILER, M. 1986. Thematic Distribution as a Heuristic for Written Discourse Function. In B. Couture (ed.), Functional Approaches to Writing: Research Perspectives. Norwood (N.J.): Ablex Publishing: 49-68. 
Fairclough, N. 1995. Media Discourse. London - New York: Edward Arnold.

Francis, G. 1989. Thematic Selection and Distribution in Written Discourse. Word 40 $(\mathrm{I}-2): 2 \mathrm{OI}-222$.

FrancIs, G. 1990. Theme in the Daily Press. Occasional Papers in Systemic Linguistics 4: 5I-87.

Fries, P.H. \& Francis, G. 1992. Exploring Theme: Problems for Research. Occasional Papers in Systemic Linguistics 6: 45-59.

Ghadessy, M. 1995. Thematic Development and its Relationship to Register and Genres. In M. Ghadessy (ed.), Thematic Development in English Text. London: Pinter: I29-I46.

Halliday, M.A.K. \& Matthiessen, C.M.I.M. 2004. An Introduction to Functional Grammar. London: Edward Arnold [3 $3^{\text {rd }}$ edition].

Halliday, M.A.K. \& Martin, J. 1993. Writing Science: Literacy and Discursive Power. London: Falmer Press.

Hawes, T. \& Thomas, S. 1996. Rhetorical Uses of Theme in Newspaper Editorials. World Englishes I5 (2): 159-170.

LAvid, J. 200o. Contextual Constraints on Thematization in Discourse: An Empirical Study. In P. Bonzon, M. Cavalcanti \& R. Nossum (eds), Formal Aspects of Context. Dordrecht - Boston: Kluwer Academic Publishers: 37-47.

Lavid, J., Arús, J. \& Moratón, L. 2009. Comparison and Translation: Towards a Combined Methodology for Contrastive Corpus Studies. International Journal of English Studies: Recent and Applied Corpus-Based Studies, special issue I: I59-173.

Lavid, J., Arús, J. \& Zamorano, J.R. 2oio. Systemic-Functional Grammar of Spanish: A Contrastive Account with English. London: Continuum.

Lavid, J., Arús, J. \& Moratón, L. forthcoming. Thematic Variation in English and Spanish Newspaper Genres: A Contrastive Corpus-Based Study. In K. Aijmer \& B. Altenberg (eds), Advances in Corpus-Based Contrastive Linguistics. Studies in Honour of Stig Johansson. Amsterdam - Philadelphia: John Benjamins.

Muntigl, P. \& Gruber, H. 2005. Introduction: Approaches to Genre. Folia Linguistica $39(\mathrm{I}-2): \mathrm{I}-\mathrm{I} 8$.

Nwogu, K. \& Bloor, T. 199I. Thematic Progression in Professional and Popular Medical Texts. In E. Ventola (ed.), Functional and Systemic Linguistics: Approaches and Uses. Berlin - New York: Mouton de Gruyter: 369-384.

Scollon, R. 1998. Mediated Discourse as Social Interaction: A Study of News Discourse. London - New York: Longman.

TiRkKONEN-Condit, S. 1996. Explicitness vs. Implicitness of Argumentation: An Intercultural Comparison. Multilingua is (3): 257-273.

VAN Dijk, T.A. 1998. Opinions and Ideologies in the Press. In A. Bell \& P. Garrett (eds), Approaches to Media Discourse. Oxford: Blackwell: 2I-63.

VAn Dijk, T.A. 1988. News as Discourse. Hillsdale (N.J.): Lawrence Erlbaum.

WANG, W. 2008a. Newspaper Commentaries on Terrorism in China and Australia: A Contrastive Genre Study. In U. Connor, E. NAgelhout \& W. RozYCKI (eds), Contrastive Rhetoric: Reaching to Intercultural Rhetoric. Amsterdam - Philadelphia: John Benjamins: I69-19I. 
WANG, W. 2008b. Intertextual Aspects of Chinese Newspaper Commentaries on the Events of 9/II. Discourse Studies io (3): 36I-38I.

WANG, W. 2007. Newspaper Commentaries on Terrorism in China and Australia: A Contrastive Genre Study. Unpublished $\mathrm{PhD}$ thesis. University of Sydney. Available online: http:// hdl.handle.net/2123/170I.

White, P.R.R. 1998. Telling Media-Tales: The News Story as Rhetoric. Unpublished PhD thesis. University of Sydney. 